\title{
An analysis of students' perspectives on e-learning participation - the case of COVID-19 pandemic
}

\author{
Shahrokh Nikou \\ Information Studies, Faculty of Social Sciences, Business and Economics, \\ Abo Akademi University, Turku, Finland and \\ Stockholm Universality, Stockholm, Sweden, and \\ Ilia Maslov \\ Faculty of Social Sciences, Business and Economics, Åbo Akademi University, \\ Turku, Finland
}

\begin{abstract}
Purpose - During the COVID-19 pandemic, educational institutions were forced to shut down, causing massive disruption of the education system. This paper aims to determine the critical factors for the intention to participate in e-learning during COVID-19.

Design/methodology/approach - Data were collected by surveying 131 university students and structural equation modelling technique using PLS-SEM was employed to analysis the data.

Findings - The results showed that the COVID-19 related factors such as perceived challenges and COVID-19 awareness not only directly impact students' intention but also such effects are mediated through perceived usefulness and perceived ease of use of e-learning systems. However, the results showed that the educational institution's preparedness does not directly impact the intention of students to participate in e-learning during COVID-19. The results also showed that the gender and length of the use of e-learning systems impact students' e-learning systems use.

Originality/value - These results demonstrated that, regardless of how well the educational institutions are prepared to promote the use of e-learning systems, other COVID-19-related challenges play a crucial role in forming the intention of students to participate in e-learning during the COVID-19 pandemic. Theoretical and practical implications are provided.
\end{abstract}

Keywords COVID-19, Distance learning, Higher education, e-learning, Online education

Paper type Research paper

\section{Introduction}

The COVID-19 pandemic is the defining global health crisis of our time, and it is adding a fair amount of complexity in how different activities are being conducted (Adnan and Anwar, 2020). Such effects are crucial on higher education, forcing all teaching and learning activities to face a sudden transition to wholly online learning contexts (Toquero, 2020). While the educational environments are still struggling with the digitalisation and digital transformation challenges and finding optimal ways to adapt, the Coronavirus pandemic has fundamentally affected their core: staff and students (Adedoyin and Soykan, 2020; Aristovnik et al., 2020; Strauß and Rummel, 2020). For them, the period is inevitably very stressful as all learning and teaching activities - e.g. all classes, meetings, seminars, supervisions and exams were forced to move online within short notice (Bao, 2020; Hodges

(C) Shahrokh Nikou and Ilia Maslov. Published by Emerald Publishing Limited. This article is published under the Creative Commons Attribution (CC BY 4.0) licence. Anyone may reproduce, distribute, translate and create derivative works of this article (for both commercial and non-commercial purposes), subject to full attribution to the original publication and authors. The full terms of this licence may be seen at http://creativecommons.org/licences/by/4.0/legalcode

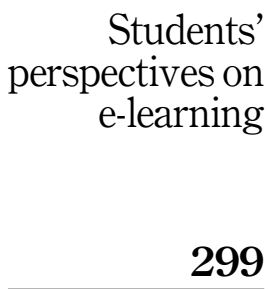

Received 21 December 2020 Revised 22 April 2021 Accepted 22 April 2021

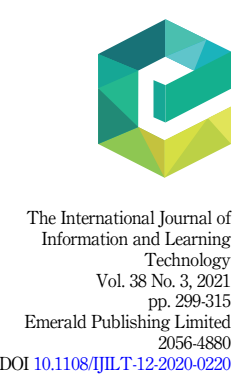


IJILT

38,3

300

et al., 2020). Though such transformation is not entirely new for such institutions, they are all now forced to move away from traditional teaching and learning structures to a virtual environment as old education models are no longer adaptable to the challenges of rapidly changing educational environments (Van Nuland et al., 2020).

In the educational environments, information and communications technology (ICT) has been extensively used to deliver information for education and learning, and e-learning has been an emerging paradigm of modern education (Sun et al., 2008). E-learning relies on the use of multiple information systems, services and technologies. Information system encompasses information service and information technology (IT), where service is understood as the use of IT. Furthermore, the user experience (UX) and usability of information technology and services also affect e-learning process, not only the technical aspects, but also the social aspects (Nakamura et al., 2017). Given the relatively recent events in terms of COVID-19 and quarantine situation worldwide, e-learning has become increasingly important as one of the optimal solutions for education (Radha et al., 2020). We argue that in order to understand better factors influencing individual decision to participate in e-learning in a worldwide quarantine situation, comprehensive research with a holistic approach is needed. Hence, we aim to address this issue by assessing students' experience in their participation in e-learning. Based on this aim, the research question guides this study is What antecedent factors impact students' intention to participate in elearning during the COVID-19 quarantine? To answer the stated research question, we develop an integrated theoretical model that encompasses several antecedent factors (perceived challenges during COVID-19, school and teachers' perceived preparedness) and constructs from Technology Acceptance Model (TAM: Davis, 1989), perceived usefulness and perceived ease of use $(\mathrm{Yu}, 2020)$. We conduct empirical research and collect data through an online survey questionnaire, focusing on university students as the target group. The data will be analysed through structural equation modelling (SEM) using SmartPLS v. 3.

The rest of this paper is structured as follows: Section 2 presents the literature review with the operationalisation of the required terminology and theoretical framework for the study. Section 3 provides the theoretical framework and hypotheses. Section 4 describes the methodology, research design, and data collection. Section 5 provides the results followed by Section 6 , providing discussions. Section 7 concludes the research and outlines the limitations and recommendations for future research.

\section{Literature review}

\subsection{E-learning and participation in e-learning concepts}

To support e-learning, learning management systems (LMS) is increasingly being used, which are e-learning software that can be used to empower teachers to enrich students' learning (Bansode and Kumbhar, 2012, p. 415). LMS is a powerful software system enhancing learning and provides automated delivery of the course content and tracking of the learning progress of the students (Dalsgaard, 2006). Sun et al. (2008, p. 1183) defined e-learning as the use of telecommunication to deliver information for education and training. Garrison and Anderson (2003) defined e-learning participation as teaching and learning facilitated and supported by Internet technologies. In this research, e-learning is defined as the overall technological system to deliver teaching, whereas participation in e-learning is the act of use of telecommunication to deliver teaching and learning within such a system. Khan (2004) defined e-learning as an iterative process that goes from the planning stage through design, production and evaluation to delivery and maintenance stages. However, there are both advantages and disadvantages to e-learning. On a positive side, e-learning allows for a learner-centred, self-paced, cost-effective way of learning and on a negative side, there is a lack of social interactions, higher degrees of frustration and confusion, with higher preparation time for instructors (Zhang et al., 2012). 
Sun et al. (2008) stated that personal perceptions about e-learning could influence attitudes and impact whether a user would intend to use to e-learning in the future. Uppal et al. (2018) and Kim and Frick (2011) mentioned that the supportiveness of the service, information quality and system quality are different aspects of e-learning quality, which could also impact the decision of the users. Moreover, Benigno and Trentin (2000) stated that e-learning is potentially affected by factors such as student characteristics, student-student interaction, learning materials, learning environment, and information technology (IT). Also, Selim (2007) mentioned that there are eight critical success factors of participation in e-learning (e.g. instructor's attitude towards and control of the technology and student motivation and technical competency). Furthermore, Sun et al. (2008) suggested that perceived e-learning satisfaction is depended on the six dimensions: learner, instructor, course, technology, design and environmental. Sun et al. (2008) concluded that learner computer anxiety, instructor attitude toward e-learning, e-learning course flexibility, e-learning course quality, perceived usefulness, perceived ease of use, and diversity in assessments were the critical factors affecting learner's perceived satisfaction.

Garavan et al. (2010) conceptualised participation in e-learning and quantitatively validated the research model. In their model, the participation in e-learning is formed by the general-person characteristics (e.g. age and social class), motivation to learn and instructional design characteristics of e-learning (content quality and learner support, feedback and recognition). Additionally, the perceived barriers and enablers to e-learning are potentially affected by the proper instructional design of e-learning. Fleming et al. (2017) identified that predictors of future use and overall satisfaction from using e-learning are low perceived complexity of the e-learning system, the knowledge of e-learning, and available technical support for e-learning. Zhang et al. (2012) presented a research model that evaluates the impact of multiple factors on the intention to continue participation in the e-learning systems. Zhang et al. (2012) concluded that the intention to participate depends directly and indirectly on the psychological safety communication climate, on the perceived responsiveness of e-learning system and self-efficacy, as well as satisfaction from the previous use of the system. Furthermore, satisfaction and membership of the community were found to affect the intention to continue participation in e-learning.

\subsection{Blended learning: boundaries between physical and virtual}

Hrastinski (2008) stated that e-learning participation does not only occur online but also takes place offline. This is mainly due to the fact that e-learning requires time and energy to learn, communication, thinking and assessing what learners have obtained from e-learning communities in more traditional learning settings. Literature on e-learning is primarily on the so-called blended learning of physical and digital learning and Anthony et al. (2020) stated that blended learning (BL) has been increasing in popularity and demand. However, recent literature on the issue seems to be dominated with the factors of educator presence in online settings, interactions between students, teachers and content, and designed connections between online and offline activities as well as between campus-related and practice-related activities.

Wilson (2009, p. 20) stated that "learning space continuum has two types of conditions at its extremities, wholly independent self-directed unstructured learning at one end and structured teacher-led didactic learning environments at the other". Furthermore, Wilson (2009) identified different places for learning spectrums, ranging from unstructured that corresponds to home, bar, cafe or gym to lecture theatre and seminar places for holding workshops. The notion of learning space continuum may become necessary when we take into consideration e-learning. As Ellis and Goodyear (2016, p. 150) identified, the "boundaries" between the physical and the virtual are become less transparent and more permeable, in addition to the greater need of students of being capable of using digital technologies to discover and construct knowledge that is meaningful to them. 
IJILT 38,3

Hence, we argue that e-learning participation cannot be defined narrowly as a specific activity in a specific context, but rather a range of activities, some of which may be even blended with the physical (more traditional) learning and interaction with teachers or other students in a more structured or unstructured manner. This could have a significant impact on the way not only e-learning, but the overall learning process is structured, including how the different technologies are used, how the instructional learning programs are structured, what are the social interrelationships between the students, instructors, organisations, and how the success of learning is measured.

\subsection{COVID-19, quarantine and e-learning}

Kaplan et al. (2020) stated that a third of the global population worldwide was on a quarantine lockdown in order to limit the spread of the COVID-19. This action led to the social distancing and thus fewer social connections, which also included closures of commercial enterprises and higher educations, resulting in limited physical presence and social interactions between the people. The impact of COVID-19 is also seen in the educational environments, with a potential to experience unparalleled transformations, just as many other human spheres of behaviour, which are facilitated by the advents in the development of IT, such as 5G (Kaplan et al., 2020, p. 4). Paraschi (2020, p. 19) stated that e-learning might even be an alternative activity that is to help communities previously relying on other activities, such as competitive educational and training e-learning programs blended with on-site summer schools in a Greek island as a replacement for tourism, which suffered greatly during the COVID-19 pandemic.

However, there are multiple challenges related to e-learning that come as a result of COVID-19. For instance, Almaiah et al. (2020) identified the critical challenges and factors of e-learning system usage during COVID-19 pandemic. In the research, the authors covered the topics of e-learning system quality, trust, culture, self-efficacy, and issues of financial support, change management and technical maintenance, all of which were mentioned as potentially influential factors of e-learning adoption. Moreover, we argue that COVID-19 pandemic is a challenge impacting the approach to e-learning, thus requiring adaptation and innovation in higher education to cope with the posed challenge. Alea et al. (2020) have evaluated the perceptions among the teachers about the impact of COVID-19 and the community quarantine on the distance learning and found multiple challenges related to it, as well as individual issues with preparedness for delivering distance learning. Also, Abbasi et al. (2020) stated that students did not prefer e-teaching over face-to-face teaching during the lockdown situation, and that administration and faculty members must take necessary measures to improve e-learning during the lockdown. Favale et al. (2020) stated that in the context of 80$90 \%$ of people in Italy staying at home during the quarantine, remote working and online collaboration exploded in an Italian university. Thus, the research on participation in elearning in the context of COVID-19 is very relevant and timely.

\subsection{Information service, information systems and information technology}

In literature, information service is defined as "a component of an information system representing a well-defined business unit that offers capabilities to realise business activities and owns resources (data, rules, roles) to realise these capabilities" (Ralyté et al., 2015, p. 39). Furthermore, Wijnhoven and Kraaijenbrink (2008, p. 93) suggested that information services are "services that facilitate the exchange of information goods with or without transforming these goods". The authors (2008, p. 114) stated that "information services have a lot in common with other types of information systems", hence implying that the information services are distinct from the information systems. Importantly, it is necessary to outline that information system (IS) is defined as any combination of information technology (IT) and people's activities using that technology (Gupta, 2000). 
Accordingly, IT consists of telecommunications, computing, and content, whereby different types of IT are represented at the intersections (e.g. Internet being partly computing, and partly telecommunications). Hence, one may wonder about the exact definitions of an information service, an information system, an information technology and what is the interrelation between them. It is essential to underline that the terms are potentially having blurry boundaries and are hard to define. For the purposes of this particular study, information service is defined as the use of information technology by people. However, the information system of e-learning at large is not considered to be limited only to LMS such as Moodle as there are many other physical and virtual information services that could facilitate e-learning. This study will try to focus on the information services of e-learning that facilitate participation over IT.

\section{Theoretical framework and hypothesis development}

Ke and Hoadley (2009) suggested that there is no "one size fits all frameworks" when evaluating online learning communities. From the literature on e-learning, there are a number of identified antecedent factors that could potentially influence participation in e-learning. Besides, factors related to the current situation of pandemic (COVID-19) may also impact the participation in e-learning. The research model for this study is developed based on the literature review outlined above. Firstly, several antecedent factors that may affect participation in e-learning are identified. Secondly, these factors are used to build a theoretical framework which will be evaluated and examined empirically.

\subsection{COVID-19 related factors}

At the time of writing the paper, the research on the COVID-19 is new, as it is a relatively recent event. Hence, the exploratory purpose of the paper is to identify potential factors that may impact e-learning participation in quarantine time. Therefore, we aim to review the most recently published studies on this topic. For example, Alea et al. (2020) have recently performed a research on the opinions of teachers concerning the preparedness and challenges that the university might face when adopting e-learning in the times of the quarantine. They empirically evaluated the (1) awareness of the COVID-related situation, (2) the teacher's readiness and school's preparedness to conduct distance learning, and (3) perceived challenges in distance learning education (Musingafi et al., 2015). In this study, nevertheless, as we plan to survey students instead of teachers, we adapt the same survey questions and modify them slightly to fit the context of our study. As such, we use (1) awareness of COVID-19, (2) perceived challenges to participate in e-learning during the quarantine, (3) perceived educational institutions preparedness [perceived teachers' preparedness and perceived school's preparedness] to conduct distance learning, as the COVID-19 related factors to examine the students' intention to e-learning participation.

Furthermore, the COVID-19 quarantine situation is understood both as the factor formulating the context of the person, forcing one to participate solely in distant e-learning, and an intervening variable, which formulates how the process of e-learning is done. Moreover, perceived usefulness and perceived ease of use of e-learning, which corresponds to the beliefs among the students that e-learning will work for them have extensively been recently used in similar studies (e.g. Almaiah et al., 2020; Al-Okaily et al., 2020b). Therefore, in addition to three COVID-19 related factors, we use the two constructs of technology acceptance model (TAM: Davis, 1989) perceived usefulness (PU) and perceived ease of use (PEOU) when developing our conceptual research model. Hence, we hypothesis:

H1. Awareness of COVID-19 has a positive effect on the intention to e-learning participation. 
IJILT

38,3

304
H1a. Awareness of COVID-19 has a positive effect on perceived usefulness.

H1b. Awareness of COVID-19 has a positive effect on perceived ease of use.

H2. Perceived challenges during COVID-19 has a negative effect on the intention to e-learning participation.

H2a. Perceived challenges during COVID-19 has a negative effect on perceived usefulness.

H2b. Perceived challenges during COVID-19 has a negative effect on perceived ease of use.

H3. Perceived educational institutions preparedness during COVID-19 has a positive effect on the intention to e-learning participation.

H3a. Perceived educational institutions preparedness during COVID-19 has a positive effect on perceived usefulness.

H3b. Perceived educational institutions preparedness during COVID-19 has a positive effect on perceived ease of use.

\subsection{Perceived usefulness of e-learning}

Perceived usefulness is defined as "the extent to which students believe that e-learning will enhance learning outcomes" (Lee et al., 2009, p. 1324). Cheng (2012) stated that perceived usefulness of e-learning impacts the intention to use e-learning and Alsabawy et al. (2016) stated that PU of e-learning is affected by IT infrastructure services, system quality, and information quality. Al-Okaily et al. (2020a) also found that PU and PEOU both positively and significantly impact the students' intention to use e-learning system during the COVID-19. Moreover, Habes (2019) found that both PU and PEOU are the two leading mechanisms supporting e-learning adaptation and usage. We argue that the PU not only has a direct impact on the students' e-learning participation but also mediates the relationships between the COVID-19 factors (awareness of COVID-19, challenges imposed by quarantine situation and educational institutions preparedness [teachers and schools]) and e-learning participation. Hence, we hypothesis that:

H4. Perceived usefulness has a significant effect on the intention to e-learning participation.

\subsection{Perceived ease of use of e-learning}

Perceived ease of use is defined as "the extent to which students believe that e-learning will be easy to use" (Lee et al., 2009, p. 1324). Cheng (2012) stated that the PEOU of e-learning impacts the intention to use e-learning, although it may be that PEOU has a weaker effect on the intention to use e-learning, than PU (Lee et al., 2009, p. 1327). It has also been found that PEOU may indirectly impact the intention to use e-learning via the mediating factor of attitude toward using e-learning (Masrom, 2007). We argue that the PEOU not only has a direct impact on the students' e-learning participation but also mediates the relationships between the COVID-19 factors (awareness of COVID, challenges imposed by COVID-19 situation and perceived teachers' preparedness and perceived school's preparedness) and e-learning participation. Hence, we hypothesis that:

H5. Perceived ease of use has a significant effect on the intention to e-learning participation.

H5a. Perceived ease of use has a significant effect on perceived usefulness. 
In the current study, our dependent variable is e-learning participation, which is measured by the student's intention to participate. There may be multiple different factors that could affect the intention of students to participate in e-learning during the quarantine situation. Prior studies in e-learning research use intention to participate in e-learning (Masrom, 2007; Tselios et al., 2011; Zhang et al., 2012; Park, 2009) as the outcome variable.

Moreover, we intend to examine several potential individual characteristics as control variables when assessing the model. We argue that the younger students are more accepting the use of IT for learning. Evidence is paradoxical in this aspect, as Fleming et al. (2017) stated that age does not impact the intention of using e-learning. Ong and Lai (2006) stated that gender might indirectly affect the acceptance of e-learning, as men and women had different perceptions of PU and PEOU of e-learning systems. The theoretical framework model is provided in Figure 1.

\section{Methodology}

The data collection was done between 15 August to 15 October 2020 through an online survey when closure of all educational institution, specifically higher education was announced by the Finnish government started from March 2020. Prior to the primary data collection, survey items (instruments) to measure five factors predicting the use of e-learning during COVID-19 among higher education students were adopted from previously validated studies and based on the adaptation process, the items for the current study were slightly modified suit the contexts of the study, COVID-19 and e-learning.

The items for measuring COVID-19 awareness (three items), perceived teachers and school preparedness (six items) and perceived COVID-19 challenges (four items) all were derived from Alea et al. (2020, pp. 134-136). Survey items for measure perceived usefulness (four items) and perceived ease of use (four items) were derived from Masrom (2007) and Davis (1989). Finally, items for measuring intention to participate in e-learning during the COVID-19 were derived from Lee et al. (2009) and Davis (1989). The model measurement and assessment of the constructs were done through the use of SmartPLS 3.2 that was guided by the procedures of Partial Least Squares Structural Equation Modelling (PLS-SEM).

\subsection{Data collection}

During the school closures, the survey instrument was distributed through an online survey application. The data were obtained only from those respondents who indicated they are currently university students. As mentioned, the data collection was formed in the course of two months, and over 350 invitations were sent. After the closure of the survey, 153 responses

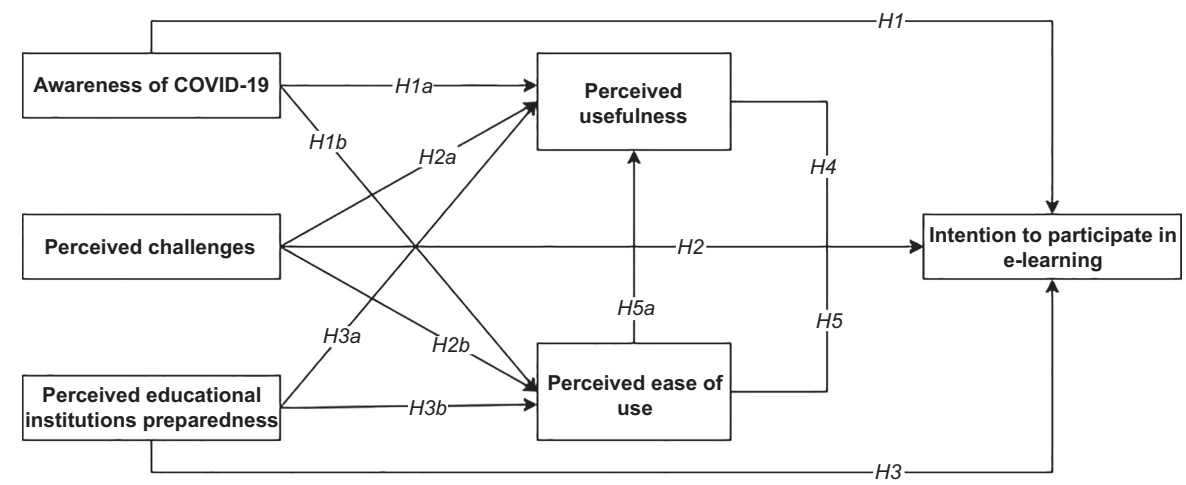

Figure 1. 
IJILT 38,3

were received. Upon further examination of the completeness of the data and removing unengaged responses or those who indicated that they are not currently students, in total, 131 responses were included in the dataset for further analysis.

\section{Results}

\subsection{Descriptive statistics}

Of the respondents, $73(55.7 \%)$ were female, while $56(42.7 \%)$ respondents were males, and two did not want to reveal their gender. The average age of respondents was 25 years old with (standard dev. $=6.1)$. Moreover, the highest degree of the respondents was as follow: high school diploma $(N=63)$, bachelor's degree $(N=40)$, master's degree $(N=19)$, and $\mathrm{PhD}$ or other $(N=9)$. We also asked respondents to indicate how long in total have they been using e-learning systems. The following information was retrieved; less than a year $(N=61)$, between one to three years $(N=37)$, more than three years $(N=32)$ and only one respondent indicated has never used such learning systems. We also asked the respondent to indicate to what extent the instructor's teaching style would impact their decision to participate in e-learning. We asked, "the instructor encourages and motivates me to use e-learning", or "the instructor's style of presentation holds my interest". The results showed that 36 students thought the teaching style of the instructor would motivate and encourage them to use e-learning systems and interestingly 23 students mentioned it does not affect their intention or the effect is not considerable. Regarding the second question, we found 28 students who believed that the instructor's presentation style would have a substantial impact on their intention to use e-learning systems to participate in e-learning. The same number of $(N=28)$ students believed that the instructor's presentation style does not at all play a role in their decision to use such systems for e-learning participation, or the effect is somewhat limited.

\subsection{Measurement results}

In the following, we report on the data analysis at the measurement model, which refers to the assessment of the measures' reliability and their validity. In doing so, we computed: (1) item (indicator) loadings and internal consistency reliability, (2) convergent validity, and (3) discriminant validity (Hair et al., 2019).

5.2.1 Item loadings and internal consistency reliability. PLS-SEM results were utilised for the item loadings in this study. Table 1 shows the detail of item loadings. As shown in Table 1 , all item loadings (except one item PCHA_2 with the slightly lower value) satisfied the recommended loading values of $>0.70$ (Hair et al., 2019). However, from the algorithm process in PLS-SEM, one item (indicator) from the COVID-19 awareness (CAWA_3) was dropped. Therefore, 24 items remained for the next step of the PLS-SEM analysis. Internal consistency reliability refers to the evaluation findings for the statistical consistency across survey items (indicators). According to Hair et al. (2019), internal consistency reliability should be reported through Cronbach's alpha $(\alpha)$ and Composite Reliability (CR). Therefore, we computed these two tests and the values achieved were all above to the recommended threshold of 0.70 (Hair et al., 2019) providing good internal consistencies.

5.2.2 Convergent validity and discriminant validity. Convergent validity is a statistical measure that assesses the construct validity, and it suggests that assessments having similar or same constructs should be positively related. Regarding the convergent validity, the value s of average variance extracted (AVE) must be reported. As shown in Table 1, all the AVE values were above the recommended threshold of 0.50 .

Discriminant validity test examines the extent to which a construct is different from other constructs (Hair et al., 2019). In order to report the values, the Fornell Larcker criterion will be used, and the AVE scores of a construct should be lower than the shared variance for all model constructs. As shown in Table 2, all the AVE scores satisfied this condition, and 


\begin{tabular}{|c|c|c|c|c|c|c|c|c|}
\hline Construct & Items & Loading & Mean & Std & $\alpha$ & $\mathrm{CR}$ & AVE & Students' \\
\hline \multirow[t]{4}{*}{ Perceived usefulness of e-learning } & PU1 & 0.94 & 3.85 & 2.05 & 0.94 & 0.95 & 0.85 & e-learning \\
\hline & PU2 & 0.91 & 3.85 & 2.03 & & & & \\
\hline & PU3 & 0.93 & 3.59 & 2.09 & & & & \\
\hline & PU4 & 0.90 & 4.59 & 1.93 & & & & \\
\hline \multirow[t]{4}{*}{ Perceived ease of use of e-learning } & PEOU1 & 0.90 & 5.28 & 1.54 & 0.91 & 0.94 & 0.79 & \\
\hline & PEOU2 & 0.89 & 5.45 & 1.56 & & & & 307 \\
\hline & PEOU3 & 0.91 & 5.16 & 1.62 & & & & \\
\hline & PEOU4 & 0.86 & 5.24 & 1.52 & & & & \\
\hline \multirow[t]{2}{*}{ COVID-19 awareness } & COVA1 & 0.87 & 6.81 & 0.74 & 0.80 & 0.91 & 0.83 & \\
\hline & COVA2 & 0.94 & 6.70 & 0.95 & & & & \\
\hline \multirow[t]{6}{*}{ Perceived educational institutions preparedness } & PEIP1 & 0.75 & 3.73 & 1.88 & 0.91 & 0.93 & 0.69 & \\
\hline & PEIP2 & 0.76 & 4.29 & 1.84 & & & & \\
\hline & PEIP3 & 0.83 & 4.85 & 1.80 & & & & \\
\hline & PEIP4 & 0.85 & 4.82 & 1.82 & & & & \\
\hline & PEIP5 & 0.90 & 4.86 & 1.86 & & & & \\
\hline & PEIP6 & 0.87 & 4.61 & 1.89 & & & & \\
\hline \multirow[t]{4}{*}{ Perceived challenges } & $\mathrm{PC} 1$ & 0.82 & 5.66 & 1.83 & 0.85 & 0.89 & 0.68 & \\
\hline & PC2 & 0.68 & 5.05 & 1.84 & & & & \\
\hline & PC3 & 0.91 & 5.53 & 1.91 & & & & \\
\hline & PC4 & 0.87 & 5.74 & 1.82 & & & & \\
\hline \multirow[t]{4}{*}{ Intention to participate in e-learning } & INT1 & 0.85 & 2.87 & 2.12 & 0.91 & 0.94 & 0.80 & \\
\hline & INT2 & 0.85 & 4.50 & 1.83 & & & & \\
\hline & INT3 & 0.93 & 3.79 & 2.04 & & & & Reflective indicator \\
\hline & INT4 & 0.93 & 3.62 & 2.06 & & & & loadings and internal \\
\hline \multicolumn{8}{|c|}{ Note(s): $\alpha=$ Cronbach's alpha; $\mathrm{CR}=$ Composite reliability; $\mathrm{AVE}=$ Average explained variance } & consistency reliability \\
\hline & COAV & INT & $\mathrm{PC}$ & $\mathrm{PEO}$ & & $\mathrm{PU}$ & PEIP & \\
\hline COVID-19_awareness & 0.910 & & & & & & & \\
\hline Intention to participate in e-learning & 0.303 & 0.891 & & & & & & \\
\hline Perceived challenges & 0.154 & -0.408 & 0.825 & & & & & \\
\hline Perceived ease of use & 0.079 & 0.538 & -0.283 & 0.85 & & & & \\
\hline Perceived usefulness & 0.205 & 0.794 & -0.346 & 0.56 & & 0.921 & & Table 2. \\
\hline Perceived educational institutions preparedness & 0.153 & 0.265 & -0.212 & 0.29 & & 0.226 & 0.828 & Discriminant validity \\
\hline
\end{tabular}

therefore, the discriminant validity was established based on the evaluation of the Fornell Larcker criterion (Fornell and Larcker, 1981).

However, as we used the PLS-SEM approach to perform the data analysis, we also assessed the discriminant validity through the Heterotrait-Monotrait Ratio of Correlations (HTMT). Discriminant validity problems also appear when HTMT values are higher than 0.90 . The construct can be similar if HTMT shows a value of $>0.90$, which in this case, it indicates the lack of discriminant validity. Table 3 shows the HTMT values, and as it is indicated, all values were lower than 0.90 .

We also examined the collinearity by reporting Variance Inflation Factor (VIF) values. The collinearity will be an issue if the VIF value is above 3.00 (Hair et al., 2019). Perceived usefulness $(\mathrm{VIF}=1.663)$ and perceived ease of use $(\mathrm{VIF}=1.559)$ are the predictor of intention to participate in e-learning during the COVID-19. Moreover, COVID-19 awareness is the predictor of perceived usefulness (VIF $=1.064)$ and perceived ease of use (VIF $=1.064)$. Perceived educational institutions preparedness predict perceived usefulness (VIF $=1.087$ ) and perceived ease of use (VIF $=1.087$ ). Perceived COVID-19 challenges predict perceived 
IJILT 38,3

308 usefulness $(\mathrm{VIF}=1.088)$ and perceived ease of use $(\mathrm{VIF}=1.088)$. Therefore, the collinearity test results show that collinearity does not emerge as an issue in this study (Hair et al., 2019).

\subsection{Structural results}

The structural model assessment was performed following Hair et al. (2019) recommendation. In order to assess the path coefficient between endogenous and exogenous constructs, the sample was bootstrapped through 5.000 sub-sampling. The results of the SRMR indicator estimating the goodness of fit of the structural model was 0.065 . The structural results showed that most of the hypotheses were supported (Table 4 and Figure 2). The outcome

\begin{tabular}{lcccccr}
\hline & COAV & INT & PC & PEOU & PU & PEIP \\
\hline COVID-19_awareness & & & & & & \\
Intention to participate in e-learning & 0.346 & & & & & \\
Perceived challenge & 0.222 & 0.431 & & & & \\
Perceived ease of use & 0.090 & 0.587 & 0.303 & & & \\
Perceived usefulness & 0.225 & 0.857 & 0.362 & 0.610 & & \\
Perceived educational institutions preparedness & 0.173 & 0.280 & 0.217 & 0.326 & 0.234 & \\
\hline
\end{tabular}

Table 3.

Discriminant validity (HTMT)
Perceived usefulness

COVID-19_awareness

Intention to participate in e-learning

0.222

0.090

0.225

0.857

0.610

0.234
Table 4.

Structural results

\begin{tabular}{lccc} 
& & $t-$ & \\
Hypothesis & $\beta$ & statistics & Sig \\
\hline H1: COVID-19_awareness $\rightarrow$ Intention to participate in e-learning & 0.192 & 3.220 & 001 \\
H1a: COVID-19_awareness $\rightarrow$ Perceived usefulness & 0.243 & 2.748 & 0.005 \\
H1b: COVID-19 awareness $\rightarrow$ Perceived ease of use & 0.081 & 0.890 & NS \\
H2: Perceived challenges $\rightarrow$ Intention to participate in e-learning & -0.186 & 2.789 & 0.005 \\
H2a: Perceived challenges $\rightarrow$ Perceived usefulness & -0.360 & 4.599 & 0.001 \\
H2b: Perceived challenges $\rightarrow$ Perceived ease of use & -0.246 & 3.167 & 0.002 \\
H3: Perceived educational institutions preparedness $\rightarrow$ Intention to & 0.022 & 0.389 & NS \\
participate in e-learning & & & \\
H3a: Perceived educational institutions preparedness $\rightarrow$ Perceived usefulness & 0.112 & 1.267 & NS \\
H3b: Perceived educational institutions preparedness $\rightarrow$ Perceived ease of use & 0.235 & 2.365 & 0.018 \\
H4: Perceived ease of use $\rightarrow$ Intention to participate in e-learning & 0.110 & 1.780 & NS \\
H5: Perceived usefulness $\rightarrow$ Intention to participate in e-learning & 0.623 & 9.225 & 0.001 \\
H5a: Perceived ease of use $\rightarrow$ Perceived usefulness & 0.484 & 6.220 & 0.001 \\
\hline & & &
\end{tabular}

Figure 2.

Structural model

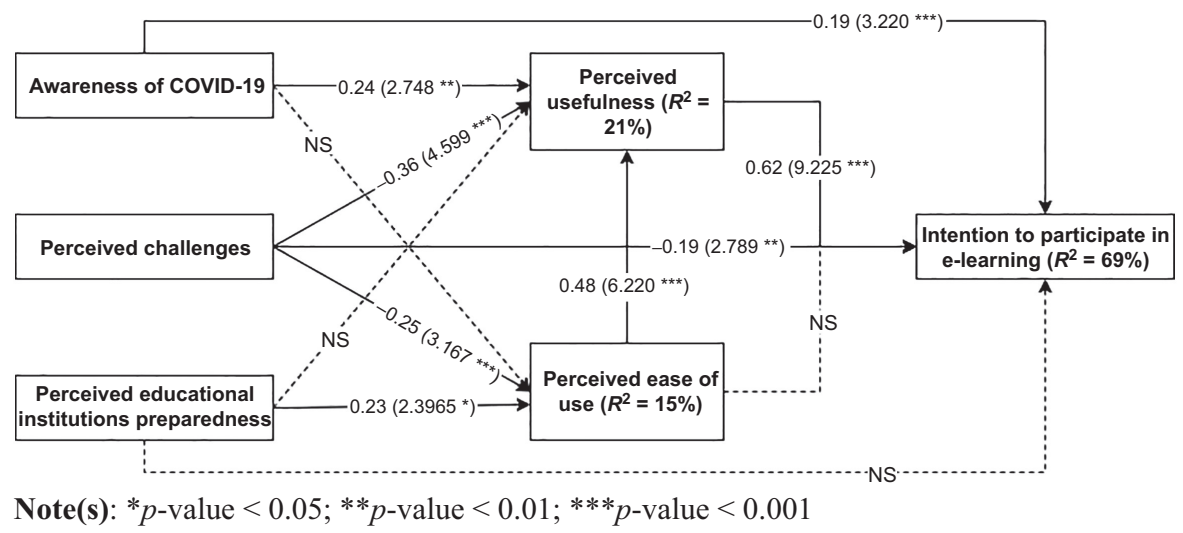


variable, i.e. intention to participate in e-learning was explained by variance of $69 \%$. Moreover, the perceived usefulness and perceived ease of use were explained by variance of $21 \%$ and $15 \%$, respectively. The SEM results showed that the path between COVID-19 awareness to intention to participate in e-learning was significant $(\beta=0.192 ; t=3.220$; $p=0.001$ ); therefore, $\mathrm{H} 1$ was supported by the model. The SEM results also showed that the path between COVID-19 awareness to perceived usefulness $(\beta=0.243 ; t=2.748 ; p=0.005)$ was significant; thus H1a was supported by the model. However, the COVID-19 awareness to perceived ease of use was not significant; thus H1b was rejected by the model.

The SEM results showed that the path between perceived challenges, as expected, negatively impact intention to participate in e-learning $(\beta=-0.186 ; t=2.789 ; p=0.005)$; therefore, H2 was supported by the model. The SEM results also showed that the path between perceived challenges during the COVID-19, as expected, negatively impact both perceived usefulness $(\beta=-0.36 ; t=4.599 ; p=0.001)$ and $(\beta=-0.246 ; t=3.167 ; p=0.002)$, thus H2a and H2b were both supported by the model. In addition, the SEM results showed that the path between perceived educational institutions preparedness to intention to participate in e-learning was not significant; therefore, $\mathrm{H} 3$ was rejected by the model. This finding is similar to Zia (2020) who also found that the curriculum and technology have a negative impact on the online classes during the COVID-19 pandemic. Furthermore, the SEM results showed that the path between perceived educational institutions preparedness to $\mathrm{PU}$ was also not significant; thus H3a was rejected by the model. However, perceived educational institutions preparedness to PEOU was significant $(\beta=0.235 ; t=2.365 ; p=0.02)$, thus H3b was supported by the model. Finally, the strongest relationship emerged between the path from perceived usefulness to participate in e-learning $(\beta=0.623 ; t=9.225 ; p=0.001)$; therefore, $\mathrm{H} 4$ was supported by the model. However, the results showed that the path between perceived ease of use to participate in e-learning was significant was not significant; thus, H5 was rejected by the model. As per path between PEOU to PU, the SEM results showed a significant effect of PEOU to PU ( $\beta=0.484 ; t=6.220 ; p=0.001)$; thus H5a was supported by the model.

We also examined the mediating effect of perceived usefulness and ease of use between the COVID-19 related factors and intention to participate in e-learning. To do so, we first accounted for the results of total indirect effects and then examined the specific indirect effects values, as PLS-SEM procedures required. The mediation test results showed the total indirect effects for the paths between COVID-19 awareness $(\beta=0.161 ; t=2.618$; $p=0.01)$, and perceived challenges $(\beta=-0.251 ; t=4.630 ; p=0.001)$ to intention to participate in e-learning were significant, indicating that there might be mediation effects in these path relationships. Therefore, we checked the specific indirect effects values and found that theses paths are mediated only through perceived usefulness. The result showed that the paths between COVID-19 awareness $(\beta=0.152 ; t=2.553 ; p=0.01)$ and perceived challenges $(\beta=-0.224 ; t=4.187 ; p=0.001)$ to intention to participate in e-learning were partially mediated through perceived usefulness. Finally, the effect of perceived educational institutions preparedness to intention to participate in e-learning was only realised through the mediating effect of PEOU-PU $(\beta=0.07 ; t=2.218 ; p=0.03)$.

\subsection{Multigroup analysis (MGA)}

The research model was further investigated to see if the demographic characteristics of the respondents impact the path relationships in the model. To do so, we used the gender, and the average time the participant used the e-learning system in their e-learning activities. These two variables were used as control variables, and then we ran multigroup analysis (MGA) with PLS-SEM. The MGA results showed that respondents are different in some paths (see Table 5). For example, the path between perceived teachers and school's preparedness to perceived usefulness was only significant for males $(\beta=0.261 ; t=1.995 ; p=0.05)$. The MGA results also showed that the path relationships between perceived challenges to (1) intention 


\begin{tabular}{|c|c|c|c|c|c|}
\hline & & & & & \\
\hline $\begin{array}{l}\text { 1JlLT } \\
282\end{array}$ & Path relationships & $\beta$ & $t$-statistics & $p$ & Sig \\
\hline & MGA results based on the respondents' gender & & & & \\
\hline & Perceived educational institutions preparedness $\rightarrow \mathrm{PU}$ & 0.261 & 1.995 & 0.05 & Male \\
\hline & Perceived challenge $\rightarrow$ Intention to participate in e-learning & -0.310 & 3.828 & 0.001 & Female \\
\hline & Perceived challenge $\rightarrow$ PU & -0.572 & 6.487 & 0.001 & Female \\
\hline & Perceived challenge $\rightarrow$ PEOU & -0.335 & 3.981 & 0.001 & Female \\
\hline 310 & COVID-19 awareness $\rightarrow$ PEOU & 0.332 & 3.406 & 0.001 & Female \\
\hline & MGA results based on the respondents' use of e-learning systems & & & & \\
\hline & Perceived educational institutions preparedness $\rightarrow$ PEOU & 0.331 & 2.161 & 0.031 & Group 1 \\
\hline Table 5. & COVID-19 awareness $\rightarrow$ Intention to participate in e-learning & 0.248 & 2.906 & 0.004 & Group 1 \\
\hline Multigroup analysis & Perceived Challenge $\rightarrow$ Intention to participate in e-learning & -0.289 & 3.114 & 0.002 & Group 2 \\
\hline results & Perceived Challenge $\rightarrow \mathrm{PU}$ & -0.279 & 2.518 & 0.01 & Group 2 \\
\hline
\end{tabular}

to participate in e-learning, (2) PU and (3) PEOU, were significant only for females. Therefore, the perceived challenges of COVID-19 could be considered as an important and influential factor influencing directly the decision-making of the students in e-learning participation. Finally, the path between the COVID-19 awareness to PEOU was only significant for females $(\beta=0.332 ; t=3.406 ; p=0.001)$.

We also divided respondents into two groups based on their use of e-learning systems; group 1 included those who indicated they have experienced and used such systems for less than a year $(N=61)$, group two for those who indicated they have experienced and used such systems for more than one year $(N=69)$. The MGA results showed that the path between perceived educational institutions preparedness and PEOU was only significant for Group 1, those who mentioned that they had used the e-learning system for less than one year. However, more differences were observed in paths between COVID-19 awareness and perceived challenges to intention to participate in e-learning, as well as the path between perceived challenges to PEOU, such that the effects of these two path relationships were only significant for respondents in Group 2 (see Table 5).

\section{Discussion}

The SEM analysis revealed that the students' intention to participate in e-learning is significantly affected by the COVID-19 awareness and perceived challenges of the pandemic. It may be because of the subjective nature of the studied phenomena, which relies on the factors that relate to the individual (i.e. awareness and perceived challenges of the pandemic). These finding are similar to Raza et al. (2020) who also stated that there is need for improving the e-learning experience among students and escalating their intention to use such learning systems. Moreover, the perceived educational institution's preparedness (i.e. teachers and schools) seems to affect the intention to participate in e-learning only through the mediating effect of PEOU-PU. It may suggest that students do not see educational institutions' preparedness by itself as a motivating factor to use the e-learning system. It may also suggest that educational institutions have not been appropriately prepared to fully utilise the functionalities of e-learning systems (e.g. usefulness) facilitating the students' learning.

Moreover, the structure results showed that the awareness of COVID-19 situation might affect the usefulness of e-learning systems, but not the extent to which the use of such systems is easy. Given the pandemic requirements for safety via the social distancing and distance learning, students might consider e-learning systems as a better and safer alternative towards conventional in campus education. In other words, students have no other alternative left other than adapting to the dynamic situation and accepting to use e-learning systems to cope with the changes in their learning modes. Interestingly and as 
expected, the perceived challenges of COVID-19 situation seem to be a very influential factor determining the perceived value of e-learning systems and the intention to use them, however, it should be noted that the effect is negative. It may suggest that emotional and stress management of students is highly crucial for e-learning in the quarantine times.

Ong and Lai (2006) found that gender might impact the participation in e-learning through the perceived usefulness and perceived ease of use of e-learning systems. In the current paper, it was found the gender of the students impact their decision in e-learning participation. We would suggest that the perceived challenges of COVID-19 situation are having a more pronounced negative effect on female students than on their male counterpart. Plausibly, this might be due to the females' perceptions of their computer self-efficacy, which is crucial for e-learning (Zhang et al., 2012). In a similar vein, we would argue that the personality variations across genders may affect the results of why COVID-19 awareness has a significant impact on PEOU and the effect is only for females and why perceived preparedness has a significant impact on PU and that the effect is realised only for males. However, the latter may also be explained by the fact that males are more things-oriented, whereas females are people-oriented (Su et al., 2009). Hence, suggesting that males could potentially see more connections between e-learning systems' functionality (usefulness) and how these were improved by the preparedness of educational institutions.

The fact that the path between perceived educational institutions preparedness and PEOU was significant for those who used e-learning systems for a year or less may indicate that the educational institution's preparedness is only able to help an inexperienced user of e-learning systems by providing sufficient support and relevant information in the times of the pandemic. More experienced users of e-learning systems may have learned how to use them; hence the preparedness did not affect their perception of ease-of-use of e-learning systems. Contrarily, for experienced users who have used e-learning systems longer than a year, it may be that they are able to put the perceived challenges in perspective to the times when e-learning was not the main and the only mode of learning. The experience of use of e-learning systems is logically expected to be highly correlated with the age and the education level; hence, it could be hard to pinpoint whether differences come from the experience or other demographic variables.

\section{Conclusions}

The education of university students has been interrupted due to COVID-19 pandemic. The current situation has imposed unique challenges of smoothly maintaining the process of teaching and learning, as such e-learning has become an immediate solution to cope with the disruption in higher education. The results of this research revealed several theoretical implications. The first being the extension of the Technology Acceptance Model (TAM: Davis, 1989) for making it relevant to the current COVID-19 situation, and its application in the context of higher education to assess students' intention to use e-learning systems. The core theoretical focus of this study was to develop a conceptual model to identify factors impacting the students' intention to e-learning participation during the COVID-19 pandemic. This paper theoretically contributes to the literature by showing that the awareness of and the perceived challenges of the COVID-19 pandemic situation were the most significant factors influencing e-learning participation during the COVID-19 pandemic. As students' awareness of COVID-19 pandemic is increased, they would be more willing to achieve their education goals through the use of e-learning systems, especially when they are socially isolated, campus education is restricted and have to perform their studies mostly online. Moreover, the findings showed that no matter how well prepared the educational institutions (teachers and schools) are, the usefulness of e-learning systems still plays the leading role in enhancing the students' intention to participate in e-learning. Surprisingly, we did not find any direct impact of ease of use of e-learning systems to the intention of e-learning 
IJILT 38,3

participation. Perhaps, blended learning (offline and online education) could be still the most proffered modes of learning for the students. In other words, a blended approach, where traditional teaching is combined with online teaching, should have ushered the students to participate in e-learning.

Alea et al. (2020) have found that there are multiple challenges in terms of educational preparedness during the COVID-19. However, in this study, it was found that educational institutions preparedness has little to no effect on the intention to participate in e-learning. Thus, the educational institutions are advised to consider the findings of this study to review their approaches to address their politics regarding e-learning in the times of the quarantine. We also found that the effects of the perceived pandemic challenges and educational institutions preparedness are different for experienced and inexperienced users of e-learning systems as well as among female and male students. As such, gender should be considered as a crucial factor in e-learning initiative taken by the educational institutions. Perceived challenges seem to have the most negative impact on women in the pandemic situation and their participation in e-learning. Sun et al. (2008) suggested that personal perceptions about e-learning affect the intention to participate in e-learning. In our study, it seems that the intention to participate in e-learning is affected by the perceptions about the contextual situation, such as about the current pandemic situation, perceived challenges it creates, and how does the educational institution prepare itself to tackle the situation.

\subsection{Limitations}

One of the drawbacks of the current research is the sample size used that can be expanded to achieve more generalisable findings. The conceptual model was developed for the purpose of this research, and therefore, the structural results and findings should be interpreted carefully. The size of the dataset and the sampling strategy might be other sources of potential errors. Since the data were collected through an online survey and during the COVID-19 pandemic situation, it is very hard to evaluate and assess whether the respondents answered questions as accurate as possible. Finally, this study took place in Finland, and might not apply to other countries due to different COVID-19 situation, regulations and imposed restriction during the current situation.

\subsection{Future research}

This research has uncovered interesting manifold insights about the different COVID-19 related factors on e-learning at educational institutions. As such, future research may utilise the conceptual model developed in this research and aim to explore further findings in other contexts. For instance, by investigating what encourages students to participate in e-learning more and why education institutions preparedness (both teachers and schools) does not account for higher intention to participate in e-learning. Students' perceptions could also be explored qualitatively. For example, why and how exactly awareness about COVID-19 encourages more intention to use e-learning systems. Future research is also advised on exploring further how educational institutions should become better prepared for future events, if they may occur, such as one we are witnessing in the current pandemic situation.

\section{References}

Abbasi, S., Ayoob, T., Malik, A. and Memon, S.I. (2020), "Perceptions of students regarding E-learning during Covid-19 at a private medical college", Pakistan Journal of Medical Sciences, Vol. 36, pp. S57-S61, doi: 10.12669/pjms.36.COVID19-S4.2766.

Adedoyin, O.B. and Soykan, E. (2020), "Covid-19 pandemic and online learning: the challenges and opportunities", Interactive Learning Environments, pp. 1-13, doi: 10.1080/10494820.2020. 1813180. 
Adnan, M. and Anwar, K. (2020), "Online learning amid the COVID-19 pandemic: students' perspectives”, Online Submission, Vol. 2 No. 1, pp. 45-51.

Al-Okaily, M., Alqudah, H., Matar, A., Lutfi, A. and Taamneh, A. (2020a), "Dataset on the Acceptance of e-learning System among universities students' under the COVID-19 pandemic conditions", Data in Brief, Vol. 32, 106176.

Al-Okaily, M., Alqudah, H.M., Matar, A., Lutfi, A. and Taamneh, A. (2020b), "Impact of covid-19 pandemic on acceptance of E-learning system in Jordan: a case of transforming the traditional education systems", Humanities and Social Sciences Reviews, Vol. 8 No. 4, pp. 840-851.

Alea, L.A., Fabrea, M.F., Roldan, R.D.A. and Farooqi, A.Z. (2020), "Teachers' covid-19 awareness, distance learning education Experiences and Perceptions towards institutional Readiness and challenges", International Journal of Learning, Teaching and Educational Research, Vol. 19 No. 6, pp. 127-144.

Almaiah, M.A., Al-Khasawneh, A. and Althunibat, A. (2020), "Exploring the critical challenges and factors influencing the e-learning system usage during COVID-19 pandemic", Education and Information Technologies, Vol. 25, pp. 5261-5280.

Alsabawy, A.Y., Cater-Steel, A. and Soar, J. (2016), "Determinants of perceived usefulness of e-learning systems", Computers in Human Behaviour, Vol. 64, pp. 843-858.

Anthony Jnr, B., Kamaludin, A., Romli, A., Mat Raffei, A.F., A_L Eh Phon, D.N., Abdullah, A., Leong Ming, G., A Shukor, N., Shukri Nordin, M. and Baba, S. (2020), "Predictors of blended learning deployment in institutions of higher learning: theory of planned behavior perspective", International Journal of Information and Learning Technology, Vol. 37 No. 4, pp. 179-196.

Aristovnik, A., Keržič, D., Ravšelj, D., Tomaževič, N. and Umek, L. (2020), "Impacts of the COVID-19 pandemic on life of higher education students: a global perspective", Sustainability, Vol. 12 No. 20, p. 8438.

Bansode, S.Y. and Kumbhar, R. (2012), "E-learning experience using open-source software: Moodle", DESIDOC Journal of Library and Information Technology, Vol. 32 No. 5, pp. 409-416.

Bao, W. (2020), "COVID-19 and online teaching in higher education: a case study of Peking University”, Human Behaviour and Emerging Technologies, Vol. 2 No. 2, pp. 113-115.

Benigno, V. and Trentin, G. (2000), "The evaluation of online courses", Journal of Computer Assisted Learning, Vol. 16 No. 3, pp. 259-270.

Cheng, Y.M. (2012), "Effects of quality antecedents on e-learning acceptance", Internet Research, Vol. 22 No. 3, pp. 361-390.

Dalsgaard, C. (2006), "Social software: E-learning beyond learning management systems", European Journal of Open, Distance and E-Learning, Vol. 9 No. 2, pp. 1-7.

Davis, F. (1989), "Perceived usefulness, perceived ease of use and user acceptance of information technology", MIS Quarterly, Vol. 13 No. 3, pp. 319-340.

Ellis, R.A. and Goodyear, P. (2016), "Models of learning space: integrating research on space, place and learning in higher education", Review of Education, Vol. 4 No. 2, pp. 149-191.

Favale, T., Soro, F., Trevisan, M., Drago, I. and Mellia, M. (2020), "Campus traffic and e-Learning during COVID-19 pandemic", Computer Networks, Vol. 176, 107290, doi: 10.1016/j.comnet.2020. 107290.

Fleming, J., Becker, K. and Newton, C. (2017), "Factors for successful e-learning: does age matter?", Education + Training, Vol. 59 No. 1, pp. 76-89.

Fornell, C.G. and Larcker, D.F. (1981), "Evaluating structural equation models with unobservable variables and measurement error", Journal of Marketing Research, Vol. 18 No. 1, pp. 39-50.

Garavan, T.N., Carbery, R., O’Malley, G. and O’Donnell, D. (2010), “Understanding participation in e-learning in organisations: a large-scale empirical study of employees", International Journal of Training and Development, Vol. 14 No. 3, pp. 155-168. 
IJILT 38,3

Garrison, D.R. and Anderson, T. (2003), E-learning in the 21 ${ }^{\text {st }}$ Century: A Framework for Research and Practice, Routledge Falmer, London.

Gupta, A. (2000), "Enterprise resource planning: the emerging organisational value systems", Industrial Management and Data Systems, Vol. 100 No. 3, pp. 114-118.

Habes, M. (2019), "The influence of personal motivation on using social TV: a uses and gratifications approach", International Journal of Information Technology and Language Studies, Vol. 3 No. 1, pp. 32-39.

Hair, J.F., Risher, J.J., Sarstedt, M. and Ringle, C.M. (2019), "When to use and how to report the results of PLS-SEM", European Business Review, Vol. 31 No. 1, pp. 2-24.

Hodges, C., Moore, S., Lockee, B., Trust, T. and Bond, A. (2020), "The difference between emergency remote teaching and online learning", Educause Review, Vol. 27.

Hrastinski, S. (2008), "What is online learner participation? A literature review", Computers and Education, Vol. 51 No. 4, pp. 1755-1765.

Kaplan, J., Frias, L. and McFall-Johnsen, M. (2020), "A third of the global population is on coronavirus lockdown - here's our constantly updated list of countries locking down and opening up", available at: https://www.businessinsider.com.au/countries-on-lockdown-coronavirus-italy2020-3 (accessed 12 December 2020).

Ke, F. and Hoadley, C. (2009), "Evaluating online learning communities", Educational Technology Research and Development, Vol. 57, pp. 487-510.

Khan, B.H. (2004), "The people-process—-product Continuum in e-learning: the e-learning P3 model”, Educational Technology, Vol. 44 No. 5, pp. 33-40.

Kim, K.J. and Frick, T.W. (2011), "Changes in student motivation during online learning”, Journal of Educational Computing Research, Vol. 44 No. 1, pp. 1-23.

Kraaijenbrink, J. and Wijnhoven, F. (2008), "Managing heterogeneous knowledge: a theory of external knowledge integration", Knowledge Management Research and Practice, Vol. 6 No. 4, pp. 274-286.

Lee, B.C., Yoon, J.O. and Lee, I. (2009), "Learners' acceptance of e-learning in South Korea: Theories and results", Computers and Education, Vol. 53 No. 4, pp. 1320-1329.

Masrom, M. (2007), "Technology acceptance model and E-learning", Proceedings of the 12th International Conference on Education, May 21-24, University Brunei Darussalam, Brunei Darussalam, pp. 1-10.

Musingafi, M.C., Mapuranga, B., Chiwanza, K. and Zebron, S. (2015), "Challenges for open and distance learning (ODL) students: experiences from students of the Zimbabwe Open University", Journal of Education and Practice, Vol. 6 No. 18, pp. 59-66.

Nakamura, W.T., de Oliveira, E.H.T. and Conte, T. (2017), "Usability and user experience evaluation of learning management systems-A systematic mapping study", International Conference on Enterprise Information Systems, Scitepress, Vol. 2, pp. 97-108.

Ong, C.S. and Lai, J.Y. (2006), "Gender differences in perceptions and relationships among dominants of e-learning acceptance”, Computers in Human Behaviour, Vol. 22 No. 5, pp. 816-829.

Paraschi, E.P. (2020), "Accessibility, tourism and social welfare: Covid19 and a new quality-of-life tourism model for the Greek islands", International Journal of Cultural and Digital Tourism, Vol. 6, pp. 10-21.

Park, S.Y. (2009), "An analysis of the technology acceptance model in understanding university students' behavioural intention to use e-learning", Journal of Educational Technology and Society, Vol. 12 No. 3, pp. 150-162.

Radha, R., Mahalakshmi, K., Kumar, V.S. and Saravanakumar, A.R. (2020), "E-learning during lockdown of Covid-19 pandemic: a global perspective", International Journal of Control and Automation, Vol. 13 No. 4, pp. 1088-1099. 
Raza, S.A., Qazi, W., Khan, K.A. and Salam, J. (2020), "Social isolation and acceptance of the learning management system (LMS) in the time of COVID-19 pandemic: an expansion of the UTAUT model”, Journal of Educational Computing Research, Vol. 59 No. 2, pp. 183-208.

Ralyté, J., Khadraoui, A. and Léonard, M. (2015), "Designing the shift from information systems to information services systems", Business and Information Systems Engineering, Vol. 57 No. 1, pp. 37-49.

Selim, H.M. (2007), "Critical success factors for e-learning acceptance: confirmatory factor models", Computers and Education, Vol. 49 No. 2, pp. 396-413.

Strauß, S. and Rummel, N. (2020), "Promoting interaction in online distance education: designing, implementing and supporting collaborative learning", Information and Learning Sciences, Vol. 121 Nos 5/6, pp. 251-260.

Su, R., Rounds, J. and Armstrong, P.I. (2009), "Men and things, women and people: a meta-analysis of sex differences in interests", Psychological Bulletin, Vol. 135 No. 6, p. 859.

Sun, P.C., Tsai, R.J., Finger, G., Chen, Y.Y. and Yeh, D. (2008), "What drives a successful e-Learning? An empirical investigation of the critical factors influencing learner satisfaction", Computers and Education, Vol. 50 No. 4, pp. 1183-1202.

Toquero, C.M. (2020), "Challenges and opportunities for higher education amid the COVID-19 pandemic: the philippine context", Pedagogical Research, Vol. 5 No. 4, pp. 1-5.

Tselios, N., Daskalakis, S. and Papadopoulou, M. (2011), "Assessing the acceptance of a blended learning university course", Journal of Educational Technology and Society, Vol. 14 No. 2, pp. 224-235.

Uppal, M.A., Ali, S. and Gulliver, S.R. (2018), "Factors determining e-learning service quality", British Journal of Educational Technology, Vol. 49 No. 3, pp. 412-426.

Van Nuland, S., Mandzuk, D., Tucker Petrick, K. and Cooper, T. (2020), "COVID-19 and its effects on teacher education in Ontario: a complex adaptive systems perspective", Journal of Education for Teaching, pp. 1-10.

Wilson, H. (2009), “The process of creating learning space”, in Radcliffe, D., Wilson, H., Powell, D. and Tibbetts, B. (Eds), Designing Next Generation Places of Learning: Collaboration at the PedagogySpace- Technology Nexus, University of Queensland, Brisbane.

$\mathrm{Yu}$, Z. (2020), "Extending the learning technology acceptance model of WeChat by adding new psychological constructs", Journal of Educational Computing Research, Vol. 58 No. 6, pp. 1121-1143.

Zhang, Y., Fang, Y., Wei, K.K. and Wang, Z. (2012), "Promoting the intention of students to continue their participation in e-learning systems", Information Technology and People, Vol. 25 No. 4, pp. 356-375.

Zia, A. (2020), "Exploring factors influencing online classes due to social distancing in COVID-19 pandemic: a business students' perspective”, International Journal of Information and Learning Technology, Vol. 37 No. 4, pp. 197-211.

\section{Corresponding author}

Shahrokh Nikou can be contacted at: shahrokh.nikou@abo.fi

For instructions on how to order reprints of this article, please visit our website:

www.emeraldgrouppublishing.com/licensing/reprints.htm

Or contact us for further details: permissions@emeraldinsight.com 